\title{
The days anthesis in relation to the floral shapes, pollen size, and S-RNase gene identifying in self- incompatibility of wild species
}

\author{
Panfeng Zhao*, Lingxia Zhao, Qian Sheng, Shanshuang Li and Huizheng Peng \\ Fudan-SJTU-Nottingham Plant Biotechnology R and D Center, School of Agriculture and Biology, Shanghai Jiaotong \\ University, Shanghai 200240, Chia.
}

Accepted 23 September, 2011

\begin{abstract}
Flowering time of tomato (Solanum.chilense) which is a self-incompatibility wild species flowers was determined using a series of landmark days. We established a correlation between the floral shapes and the days before anthesis. The model of tomato flower development schedule was then used to analyze the size of bud, anther, style, and the pollen scanning electron microscope (SEM) in the days before anthesis. Two new S-RNase genes of the Solanum .chilense which was the stylar SI genes were cloned. The structure of the two S-RNase was also analyzed. Finally, the different topology of the phylogenetic trees produced using available S-RNase sequences suggests that the S-RNase have different evolutionary histories.
\end{abstract}

Key words: Solanum.chilense, flower development, self-incompatibility (SI), the pollen SEM

\section{INTRODUCTION}

Research in plant developmental biology has progressed very rapidly in the past decade due to the application of molecular biology techniques, the isolation and characterization of various developmental mutants, and the cloning of genes specifically involved in different stages of plant development. It has been established that floral organ development is controlled by the differential expression of tissue- and organ-specific genes (Meyerowitz, 1998; Theissen et al., 2000). Such genes may be involved in organ/tissue differentiation by triggering the regulatory cascade of key genes controlling the identity of floral organs, that is, the "ABC" model of floral development (Coen and Meyerowitz, 1991; Weigel and Meyerowitz, 1994; $\mathrm{Ng}$ and Yanofsky, 2000). The ontogeny of tomato (Lycopersicon esculentum cv. sweet cherry) flowers was subdivided into 20 stages using a series of landmark events (Vladimir Brukhin et al., 2003). However, these models are not suitable to the research of pollination biology. Self-incompatibility (SI) is a genetic

\footnotetext{
*Corresponding author: E-mail: shuainanhai81517@sohu.com.
}

mechanism found in many flowering plants that acts to inbreeding (De Nettancourt, 2001). In the best- reduce the negative fitness effects associated with understood examples, $\mathrm{SI}$ is controlled by a single genetic $\mathrm{S}$ locus with many $S$ alleles: styles reject pollen grains when both express the same $S$ specificity. So, the problem that whether the self pollen is rejected by itself style is the key problem . The better method to answer this problem is the pollination biology. In this paper, we established a correlation between the floral shapes and the days before anthesis. And the model of tomato flower development schedule was then used to analyse the size of bud, anther, style, and the pollen EMS in the days before anthesis, the most important is that we know which day of the days before anthesis is the day of the viable pollen.

Using our model of tomato flower development schedule on tomato flower development, we have been able to identify critical stages at which major pollens is the viable pollen. We also show that the flower development schedule can be used to analyse self-incompatibility of wild species pattern of pollination in tomato flowers. And we cloned two new the S-RNase genes illustrated self-incompatibility (SI). 
Table 1. Tert butyl alcohol (TBA), dd $\mathrm{H}_{2} \mathrm{O}$ and ethanol concentration gradations.

\begin{tabular}{ccccc}
\hline \multirow{2}{*}{ Gradations } & \multicolumn{4}{c}{ Name and ratio (\%) } \\
\cline { 2 - 5 } & TBA & $\mathbf{d d H}_{\mathbf{2}} \mathbf{O}$ & Ethanol & TBA:ddH $\mathbf{O}$ : ethanol (final concentration) \\
\hline 1 & 10 & 40 & 50 & $10: 40: 50$ \\
2 & 20 & 30 & 50 & $20: 30: 50$ \\
3 & 35 & 15 & 50 & $35: 15: 50$ \\
4 & 50 & 0 & 50 & $50: 0: 50$ \\
5 & 75 & 0 & 25 & $75: 0: 25$ \\
6 & 100 & 0 & 0 & $100: 0: 0$ \\
7 & 100 & 0 & 0 & $100: 0: 0$ \\
\hline
\end{tabular}

\section{MATERIALS AND METHODS}

\section{Materials}

Seeds of self-incompatibility (SI) S. chilense (LA0130) and selfcompatibility (SC)S. habrochaites (LA0094) were obtained from the Charles Rick Tomato Genetics Resource Center at the University of California Davis http://tgrc.ucdavis.edu/index.aspx and were germinated in peat pellets and seedlings with three to four leaves were transferred into $15 \mathrm{~cm}$ plastic pots containing the perlite :peat $(1: 1)$. The plants were grown in greenhouse under a thermoperiod of $26 / 20^{\circ} \mathrm{C}$ (day/night). Plants were supplied every week with a commercial fertilizer.

\section{Methods}

\section{Flower development schedule define}

Inflorescence and flower sampling were performed on 2-month-old plants after the production of three inflorescences. Then flower development schedule was defined.

\section{Scanning electron microscopy}

Samples were fixed in $69 \%$ acetone/29\% $\mathrm{ddH}_{2} \mathrm{O} / 2 \%$ glutaraldehyde $(100 \%)$ for $24 \mathrm{~h}$ at $4{ }^{\circ} \mathrm{C}$, washed, dehydrated with 30,50 and $70 \%$ ethanol for 15 to 20 min separately and samples were then dried as following tert butyl alcohol(TBA), $\mathrm{ddH}_{2} \mathrm{O}$, and ethanol concentration grads (Table1). Every grad needs 15 to 20 min and sputtered with gold. Specimens were examined by SEM (NOVA NanoSEM 230) at an accelerating voltage of $5.00 \mathrm{kV}$, magnification of $1000 \mathrm{x}$, electron microscope detector of LVD. Images were saved as digital files.

\section{Pollen vitality, pollinations and pistil staining}

The pollen vitality was tested by the acetocarmine method. Flower buds were emasculated one day prior to anthesis (Brukhin et al., 2003) and pollinated with self pollen. Pollinated pistils were collected after at $6,24,30,32$ and $48 \mathrm{~h}$ unless otherwise noted, and fixed, cleared and stained with aniline blue fluorochrome (ABF, 4'4-[carbonyl bis (benzene 4,1-diyl) bis (imino)] bis benzenesulphonic acid from Biosupplies, Victoria, Australia) in 0.1M K3PO4 as a stain for callose in pollen tube walls (Kearns and Inouye, 1993). Slide-mounted pistils were examined using a BX51 microscope (Leica Microsystems, Wetzlar, Germany) running IPLab Version 4 Software (BD Biosciences, Rockville, MD) coupled with a Hamamatsu C4742-95 camera (Bridgewater, NJ). Images were captured at $100 \times$ magnification using a DAPI emission filter.

\section{Primer design and PCR}

PCR amplification of $S$-RNase genes was performed as described by Kondo et al. (2002). Two sets of degenerate outer and inner primers were used to amplify S-RNase sequences: outer $\mathrm{C} 2$ primer LP-5A:AA(T/C)TT(T/C)AA(C/G/A)AT(T/C/A)CA(T/C)GG, inner C2 primer LP-5B: $\quad A T(T / C / A) C A(T / C) G G(C / G)(G / C) T(T / A / G)$ TGGCC(A/T/G)GAT, outer C5 primer LP-3A: GGT $(T / C)(G / T / A) A(A / G) A C A T A T(G / A / T) C C$, and inner C5 primer LP-3B: ATAT(G/A/T)CC(T/A)A(T/C)(T/C)TC(A/C)(G/T/A)(T/G/A)(T/A)AGTT CAA. Outer primer (LA-5A, LA-3A; 20 cycles: $95^{\circ} \mathrm{C}, 30 \mathrm{sec} ; 50^{\circ} \mathrm{C}$, $\left.60 \mathrm{sec} ; 72^{\circ} \mathrm{C}, 60 \mathrm{~s}\right)$ PCR products were diluted (1:20) and amplified using the inner set (that is, LA-5B, LA-3B; 20 cycles: $95^{\circ} \mathrm{C}, 30 \mathrm{~s}$; $\left.50^{\circ} \mathrm{C}, 60 \mathrm{~s} ; 72^{\circ} \mathrm{C}, 60 \mathrm{~s}\right)$.

\section{Cloning and DNA sequencing}

PCR products were separated in $1 \%$ agarose gels, and cloned into pMD18-T vector system (TaKaRa) for sequencing. S-RNase genes identified in the present study are registered in GenBank database as ZS4 (JN226563), ZS5 (JN226564). All evolutionary analyses and alignments were performed using DNAMAN and ClustalW.

\section{RESULTS AND DISCUSSION}

\section{Defining flowering time}

S. chilense belongs to the Solanaceae family. It is a plant featuring a sympodial growth habit of the main shoot and axillary branches; after producing eight to ten leaves, the vegetative meristem transformed into the inflorescence meristem. The next vegetative apex was formed by the lateral bud in the axil of the leaf closest to the apical meristem. Later, the growth of this meristem pushed the inflorescence meristem to the side. The inflorescence meristem ultimately appeared as a lateral monochasial inflorescence, which is a dichotomously branched scorpioid uniparous cyme of six to ten flowers on each branch (Figure 1). Flowers contained five sepals, alternating with five petals, five anti-sepalous stamens forming a cone around the style (lateral cohesion of anthers by the interweaving of hairs) and two fused 


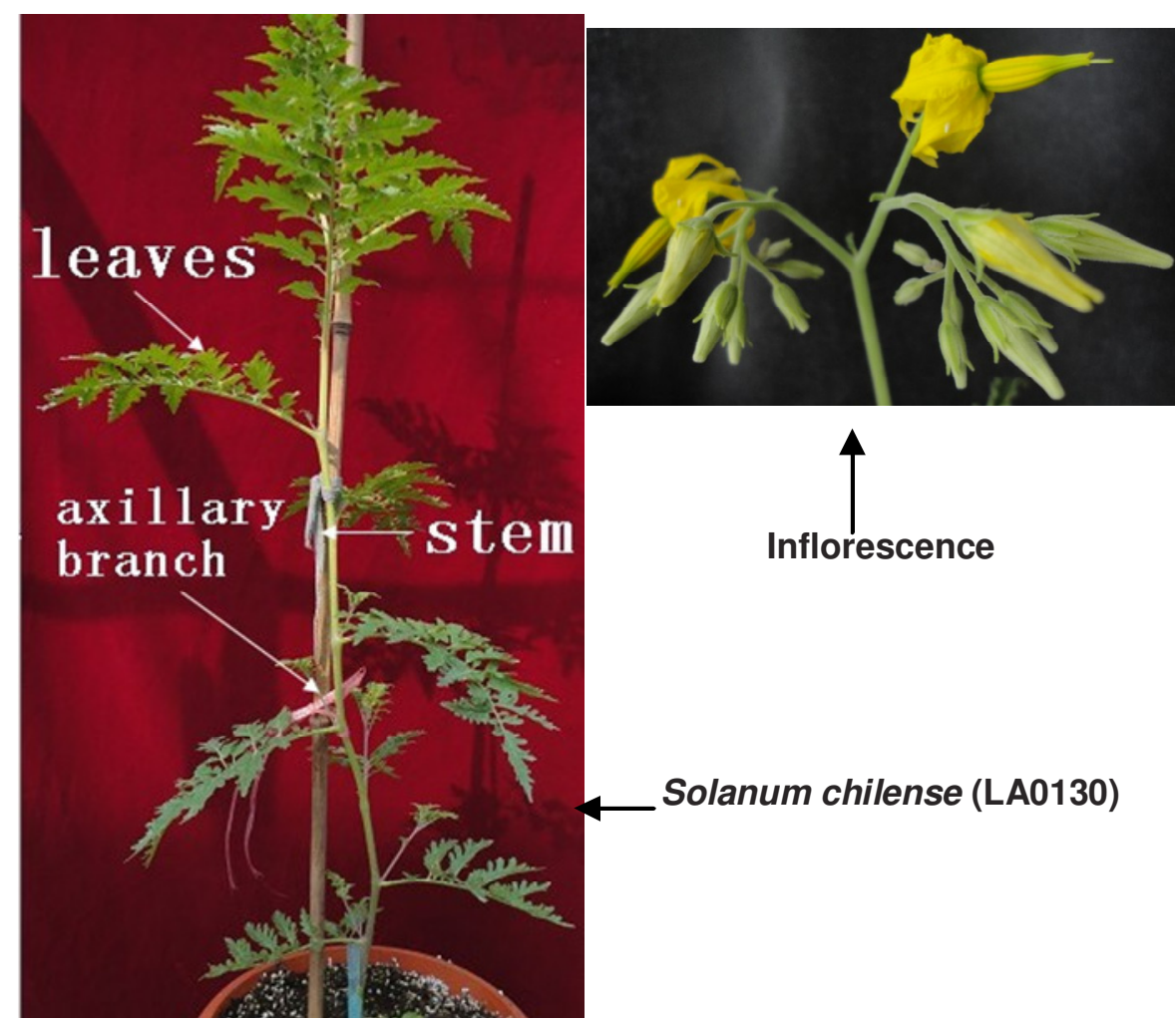

Figure 1. Solanum chilense (LA0130) and Inflorescence.

carpels forming a style. The flower was partly gamosepalous. In mature tomato flowers, stamens were shorter than the style, and the anthers formed a tube around the style.

S. chilense (LA0130), the days before anthesis and the days after anthesis is presented in Figure 2. The developmental process has been subdivided into several days (the days before anthesis and the days after anthesis). The following sections detail the comparative development of flower in relation to the days before anthesis and the days after anthesis (Figure 2).

\section{The size of floral organ at the days before anthesis}

The very early stages of flower development (ranging from 200 to $1,000 \mathrm{~mm}$ in length) have already been described (Sawhney and Greyson, 1972; Chandra and Sawhney, 1984; Rasmussen and Green, 1993) and the size of floral organs summarized as 20 stages (Vladimir et al., 2003). The data reported here that showed in relation to the days before anthesis and the bud forms, the bud size, the anther size, the style length (Table 2).

Comparative the days before anthesis in relation to the bud size, the anther size, the style length showing that the bud size and the anther size continued to grow not to stop from the 7 days before anthesis to the 0 day before anthesis.

\section{Pollen SEM}

The size of pollen increased from the 7 days before anthesis to the 3 days before anthesis, and then decreased until the 0 days before anthesis (Figures 3 and 4). The dehydration of pollen will happen at the 3 days before anthesis. Tomato pollen development is presented in Figure 5. The developmental process was subdivided into these stages, as follows: stage 1 pollen mother cell, stage 2 tetrad, stage 3 free microspores, stage 4 uninucleate microspores, stage 5 immature pollen grain, stage 6 mature pollen grain. The dehydration process of pollen happened from the stage 5 to the stage 6 . So the 3 days before anthesis, the dehydration process of pollen happened from the stage 5 to the stage 6 . The pollen have became the mature pollen before the 2 days before anthesis in Solanum chilense (LA0130).

\section{The pollen vitality of the days after anthesis}

Testing techniques of plant pollen viability were summarized as follows: staining method, germination method and pollination in field method, etc. But the staining method was the convenient and efficient method. In this paper, the pollen vitality was tested by the acetocarmine method. The pollen exists the vitality from the 0 days after anthesis to the 6 days after anthesis. Pollination can 


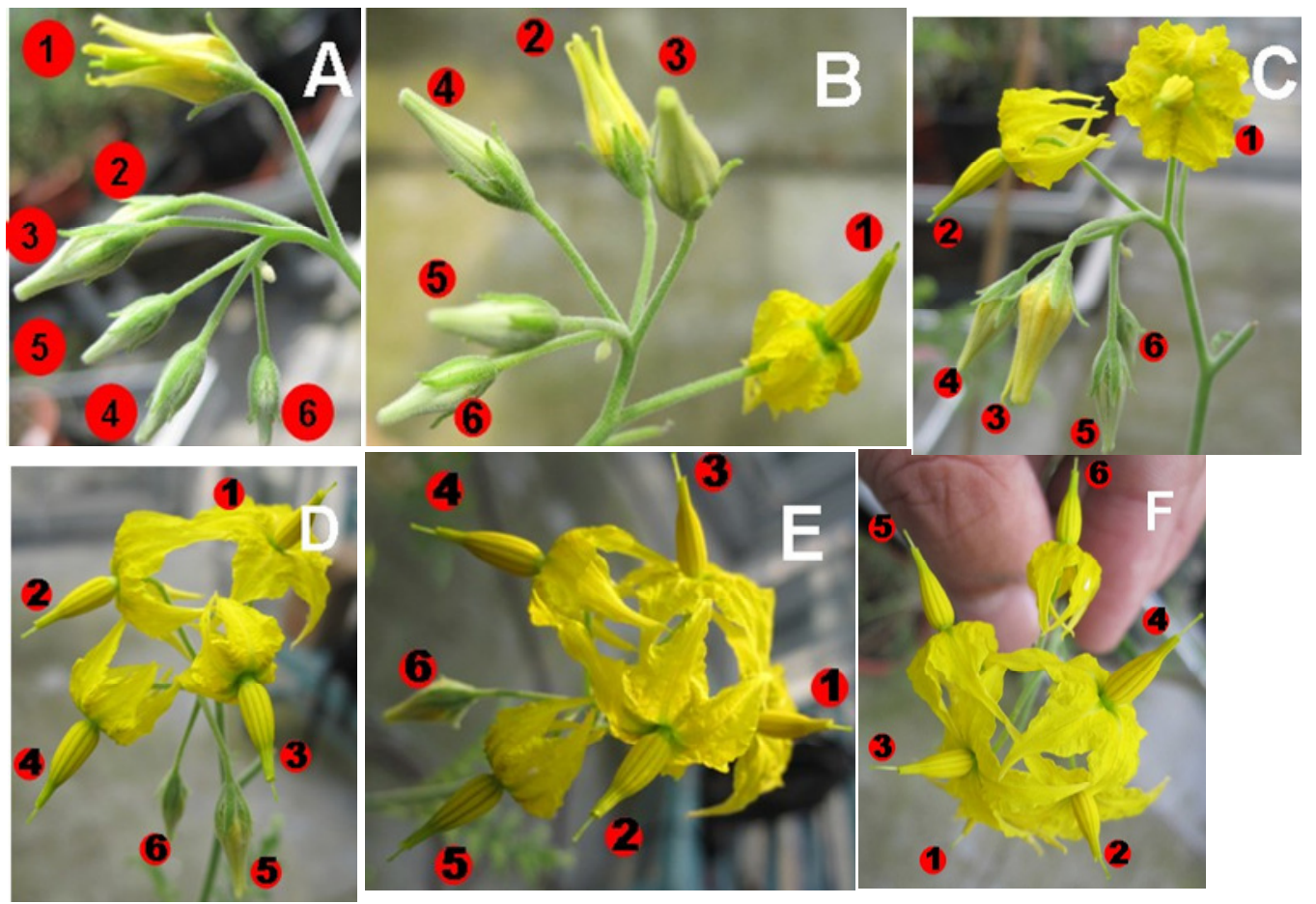

Figure 2. Solanum chilense (LA0130) Inflorescence. A-No flower flowering time : 2011-05-30 ( am 10:00; B-1 The day of flowering day (Oday) time : 2011-05-31 ( am 9:00); C-2 The day of flowering day (Oday) time : 2011-06-01 ( am 9:00); D-3 4 The day of flowering day (Oday) time : 2011-06-02 ( am 9:00 ) ; E-5 The day of flowering day (0day) time : 2011-06-03 ( am 9:00 ); F-6 The day of flowering day (0day) time : 2011-06-04 ( am 9:00) ; Drawing a conclusion from the Figure 2 : The floral shapes of the days before anthesis in $\mathrm{B}: 1$ the floral shapes of the 0 day before anthesis, 2 the floral shapes of the 1 day before anthesis, 34 the floral shapes of the 2 days before anthesis, 5 the floral shapes of the 3 days before anthesis, 6 the floral shapes of the 4 days before anthesis ; The days after anthesis in F: 1 The 4 days after anthesis, 2 The 3 days after anthesis, 34 The 2 days after anthesis, 5 The 1 day after anthesis, 6 The 0 day after anthesis.

be done in these days.

\section{Pollination with self pollen}

Pollen tube growth in self pollinations was quantified, as shown in Figures 7 and 8 . After $48 \mathrm{~h}$, pollen tubes reached the ovary in self pollinations of a SC accession LA0094 and didn't reach the ovary in self pollination of a $\mathrm{SI}$ accession LA0130 as predicted. In the SI accession LA0130, the pollen tube almost stopped growing from 6 to $24 \mathrm{~h}$, started growing after $24 \mathrm{~h}$, but don't reached the ovary. In the SC accession LA0094, the pollen tube constantly grew, reached the ovary and fruiting finally.

\section{Identify S-RNase genes of SI accession LA0130}

PCR and sequence analysis were used to detect the identity of S-RNase genes. Degenerate PCR primers were designed using sequences encoding conserved regions C2 and C5 (loerger et al., 1991) and used to identify the S-RNase genes. S-RNase genes were identified by the presence of additional conserved regions $\mathrm{C} 3$ and $\mathrm{C} 4$ and by the presence of an intron characteristic of all solanaceous S-RNase genes (Igic and Kohn, 2001) (Figure 9).

Sequences in the tree and their accession numbers are Lycium cestroides (HM195097.1), Lycium cooperi (HM195096.1), Lycium pallidum (HM195095.1), Petunia hybrida S3( U07363.1), Petunia integrifolia S13 (AF301174.1), Solanum peruvianum SP17(HM357228.1), Solanum carolinense N-SC(L40551.1), Solanum chilense S11(EF680110.1), Solanum chacoense S-arg (DQ007316.1), Lycopersicon hirsutum LhgSRN-2(AB072479.1), Solanum chmielewskii LcwSRN-1(AB072477.1), Solanum neorickii LpfSRN-2(AB072476.1), L.peruvianum (X76065.1), Physalis crassifolia S9(L46661.1), Physalis 
Table 2. The size of floral organ at the days before anthesis.

\begin{tabular}{|c|c|c|c|c|c|c|}
\hline & \multicolumn{6}{|c|}{ Bud form bud anther style the days before anthesis } \\
\hline & Length (mm) & width $(\mathrm{mm})$ & Length (mm) & width (mm) & length (mm) & day \\
\hline$A$ & & & 10.17 & 2.79 & 13.00 & 0 \\
\hline B & 12.76 & 4.89 & & & & 2 \\
\hline C & 11.48 & 4.05 & & & & 3 \\
\hline$D$ & 10.09 & 3.41 & & & & 4 \\
\hline $\mathrm{E}$ & 8.22 & 3.04 & & & & 5 \\
\hline $\mathrm{F}$ & 6.83 & 2.48 & & & & 6 \\
\hline $\mathrm{G}$ & 6.04 & 2.45 & & & & 7 \\
\hline $\mathrm{H}$ & 5.6 & 2.28 & & & & Buddies \\
\hline 1 & 4.81 & 2.25 & & & & Buddies \\
\hline
\end{tabular}
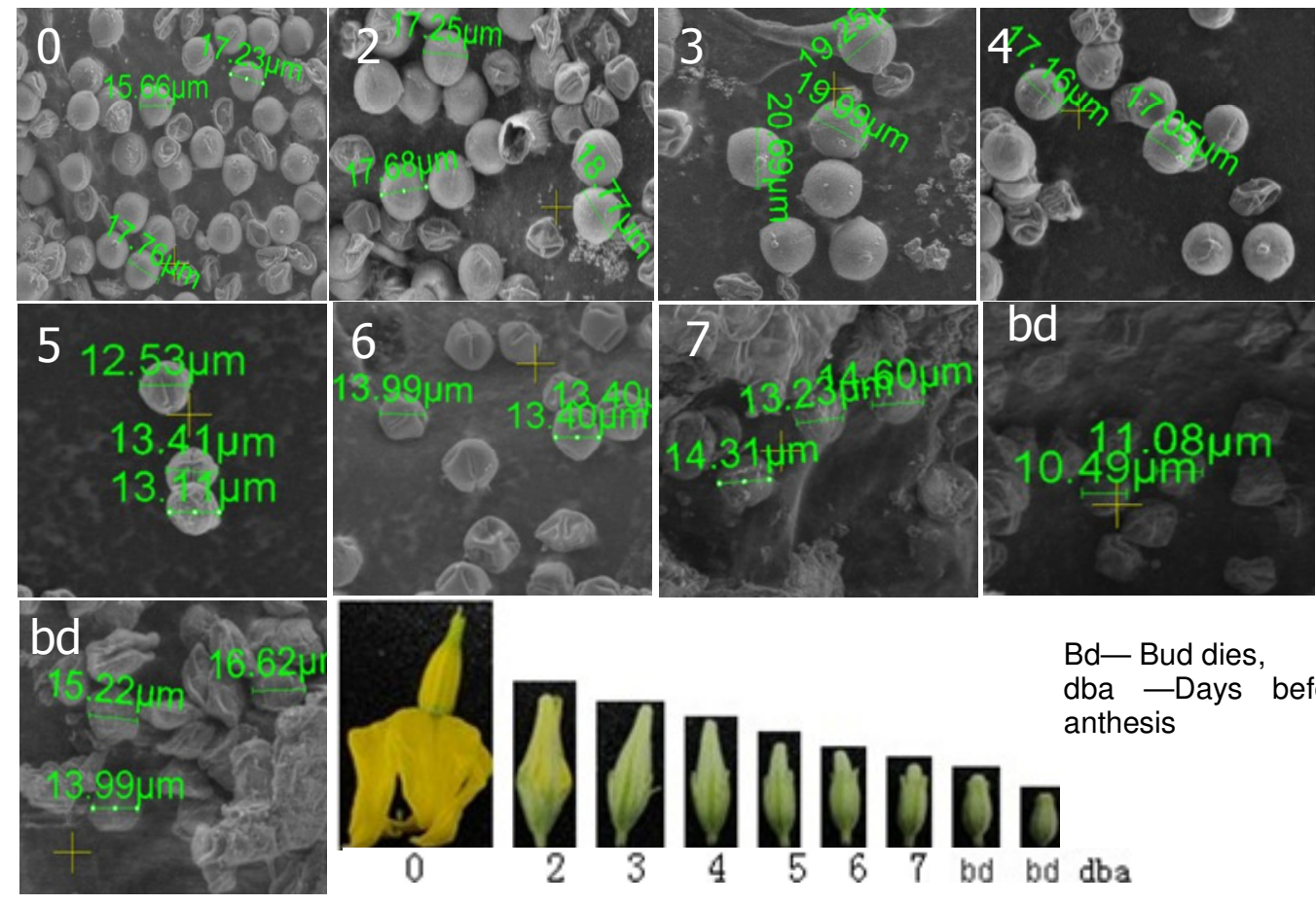

Figure 3. EMS of Pollen in relation to the pollen form of the days before anthesis (dba).

cinerascens PCIN4(AF058933.1), Physalis longifolia S5(AF374420.1), Witheringia solanacea S23(AY454121.1), Witheringia maculate S6(AF102073.1), Nicotiana tabacum relic (AJ011532.1), Nicotiana sylvestris (AJ002296.1), Nicotiana alata (GQ375153.1), lochroma loxense S2(EU382087.1), lochroma gesnerioides S2(EU382083.1), lochroma cyaneum S1(EU382081.1), lochroma australe S3( EU382080.1), Vassobia breviflora S2(EU382085.1), Vassobia breviflora S1(EU382084.1), Dunalia brachyacantha S1(EU382077.1), Eriolarynx lorentzii
S3(EU382076.1), Eriolarynxm lorentzii S2(EU382075.1), Eriolarynx lorentzii S1(EU382074.1), Solanum habrochaites S-hab-1 (GU361144.1).

A Neighbor-joining tree was constructed using the PHYLIP program and is shown in Figure 10. The Neighbor-joining tree grouped the ZS4, ZS5, Solanum chmielewskii LcwSRN-1, Solanum chilense S11 in the same cluster, in agreement with the ZS4 and ZS5 are of the S-RNase family.

In the past study, the ontogeny of tomato (Lycopersicon esculentum cv. sweet cherry) flowers was subdivided into 


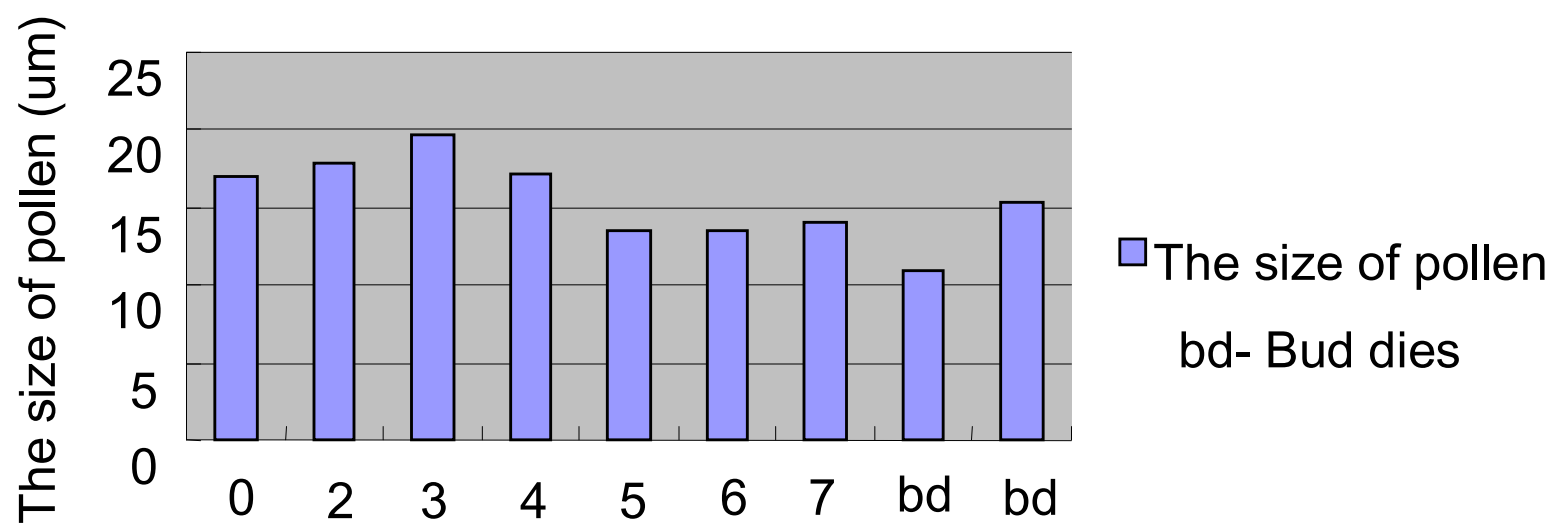

Figure 4. The size of Pollen in relation to the days before anthesis (dya).

\section{Free microspores}

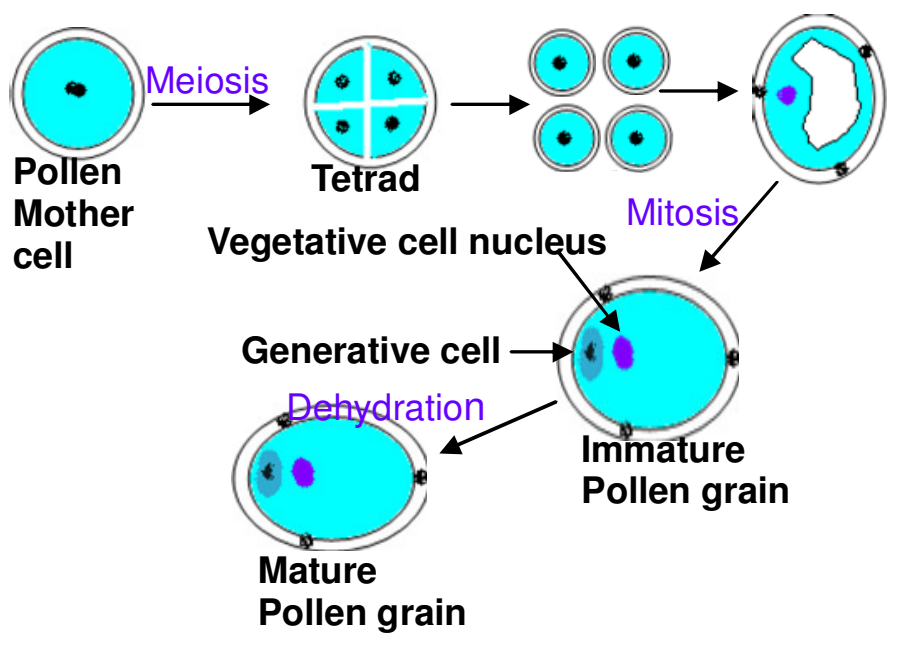

Figure 5. The developmental process of tomato pollen.

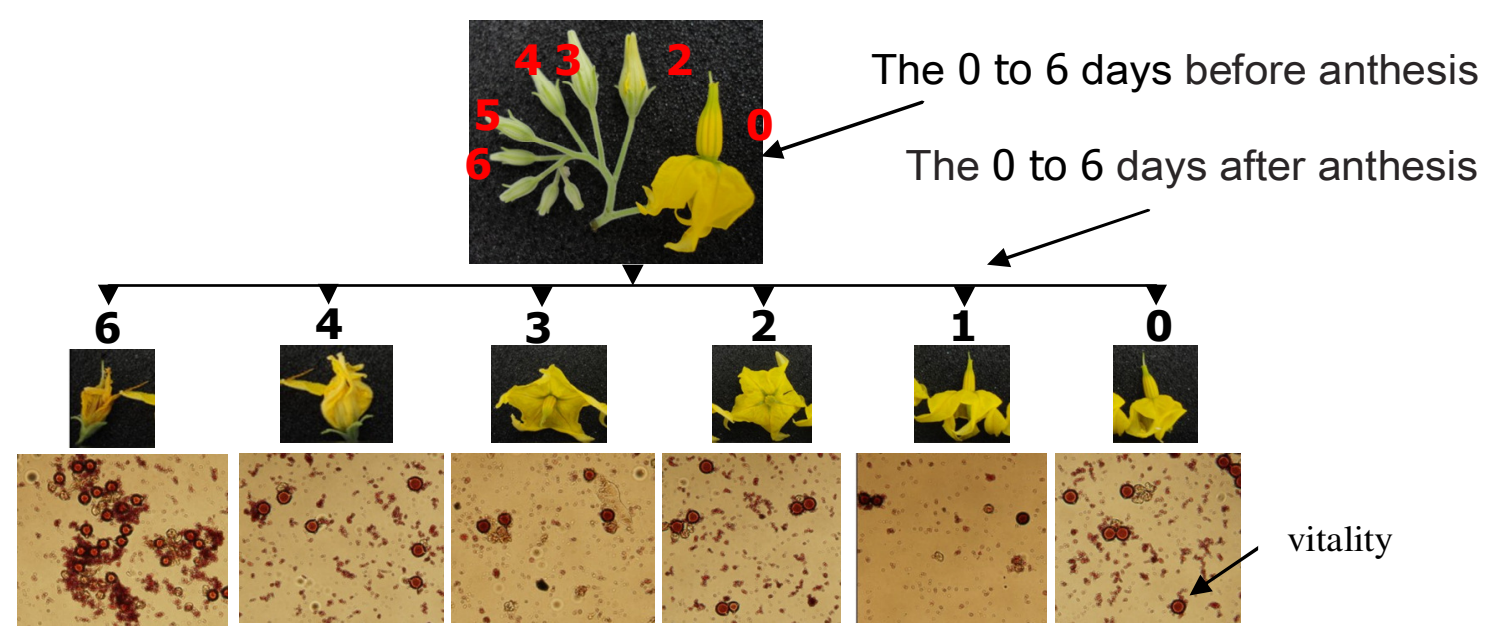

Figure 6. The pollen vitality of the days after anthesis 

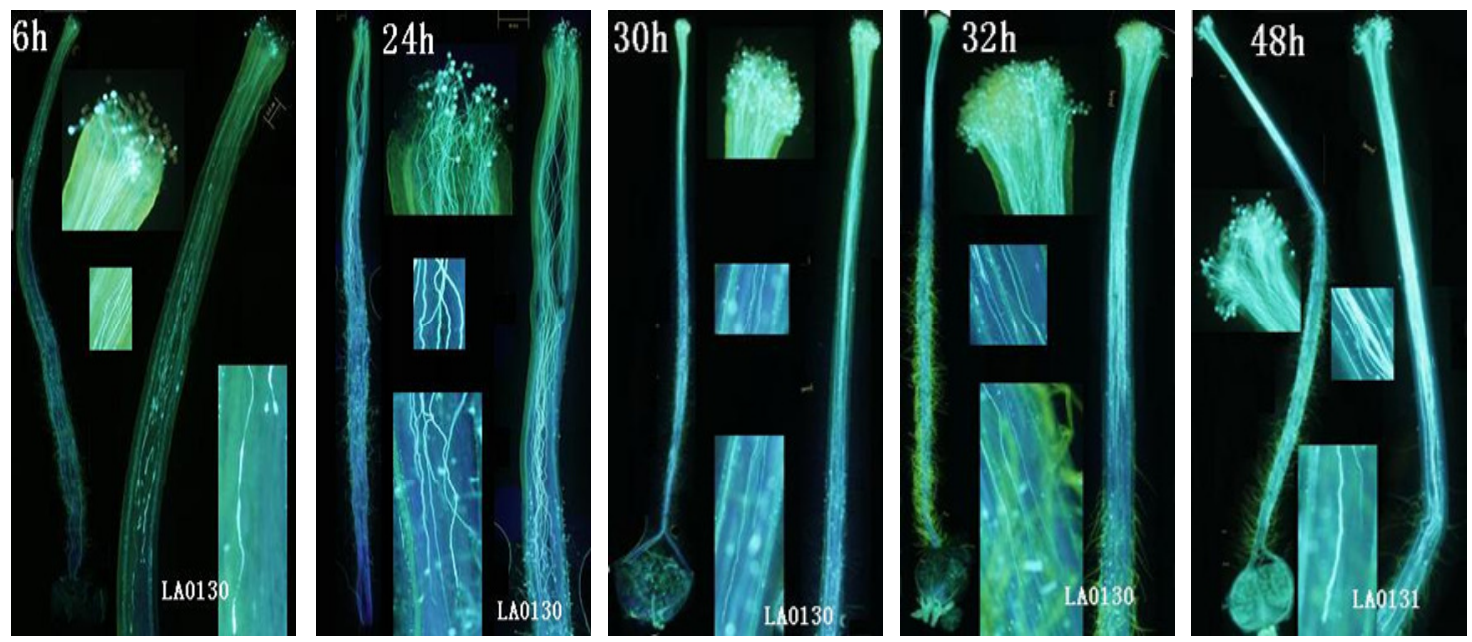

a
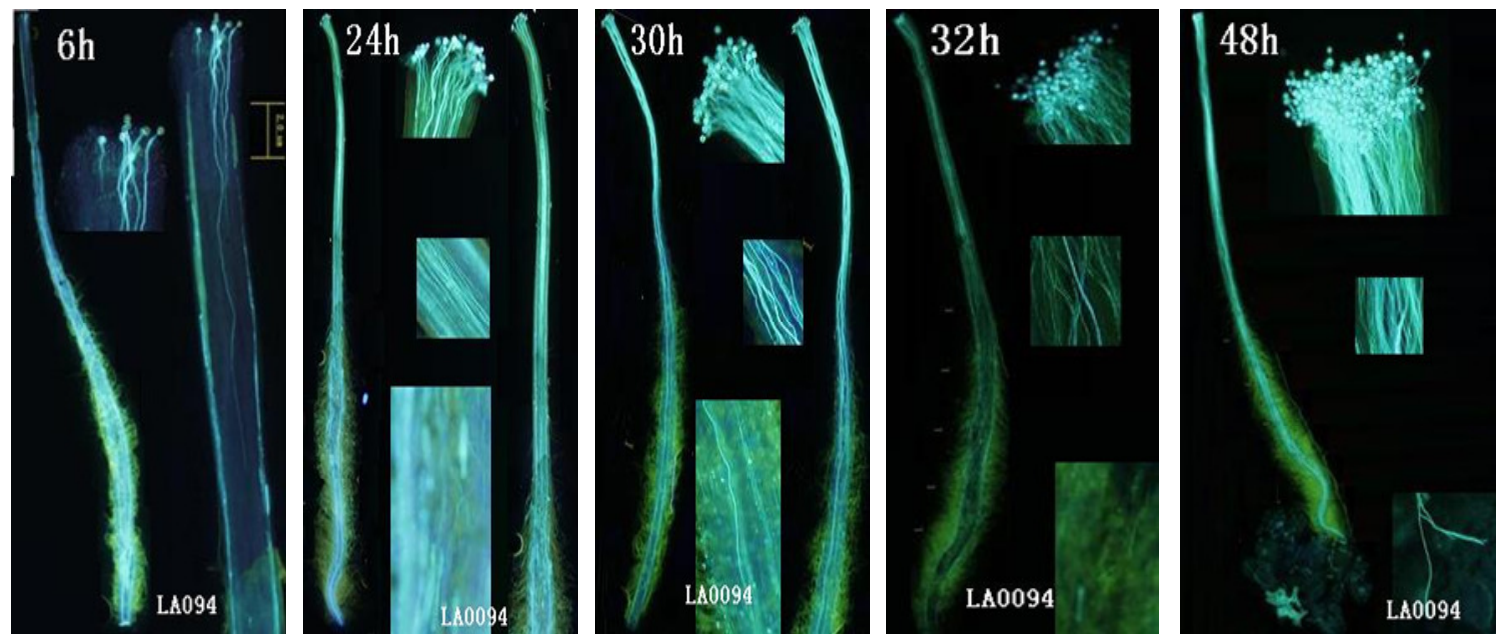

b

Figure 7. SI and SC pollen tube growth in self pollinations.

20 stages using a series of landmark events (Vladimir et al., 2003). The 20 stages were used to study the ontogeny of tomato, which was not suitable for use in the studying of pollination biology. In this study, we detailed the comparative development of flower in relation to the days before anthesis and the days after anthesis and established the model of tomato flower development schedule, the correlation between the floral shapes and the days before anthesis, the days after anthesis. And then the model of tomato flower development schedule was used to analyse the size of bud, anther, style, and the pollen SEM in the days before anthesis. Also, we established the correlation between the pollen vitality and the days after anthesis and used to study the pollination biology of the self-incompatibility of wild species. And we knew which day was the best day for the pollination. In addition, this paper describes the identifying of the SRNase genes of the Solanum.chilense (LA0130) which will be useful to us in future study.

In conclusion, we have constructed a detailed reference model of the correlation between the floral shapes and the days before anthesis and the pollen vitality of the days after anthesis for the later study of the pollination and especially for self-incompatibility of wild species pollination.

\section{ACKNOWLEDGEMENTS}

We thank the Charles Rick Tomato Genetics Resource Center at the University of California Davis for supply the seeds of tomato and Dr. Qian Sheng for experimental help 


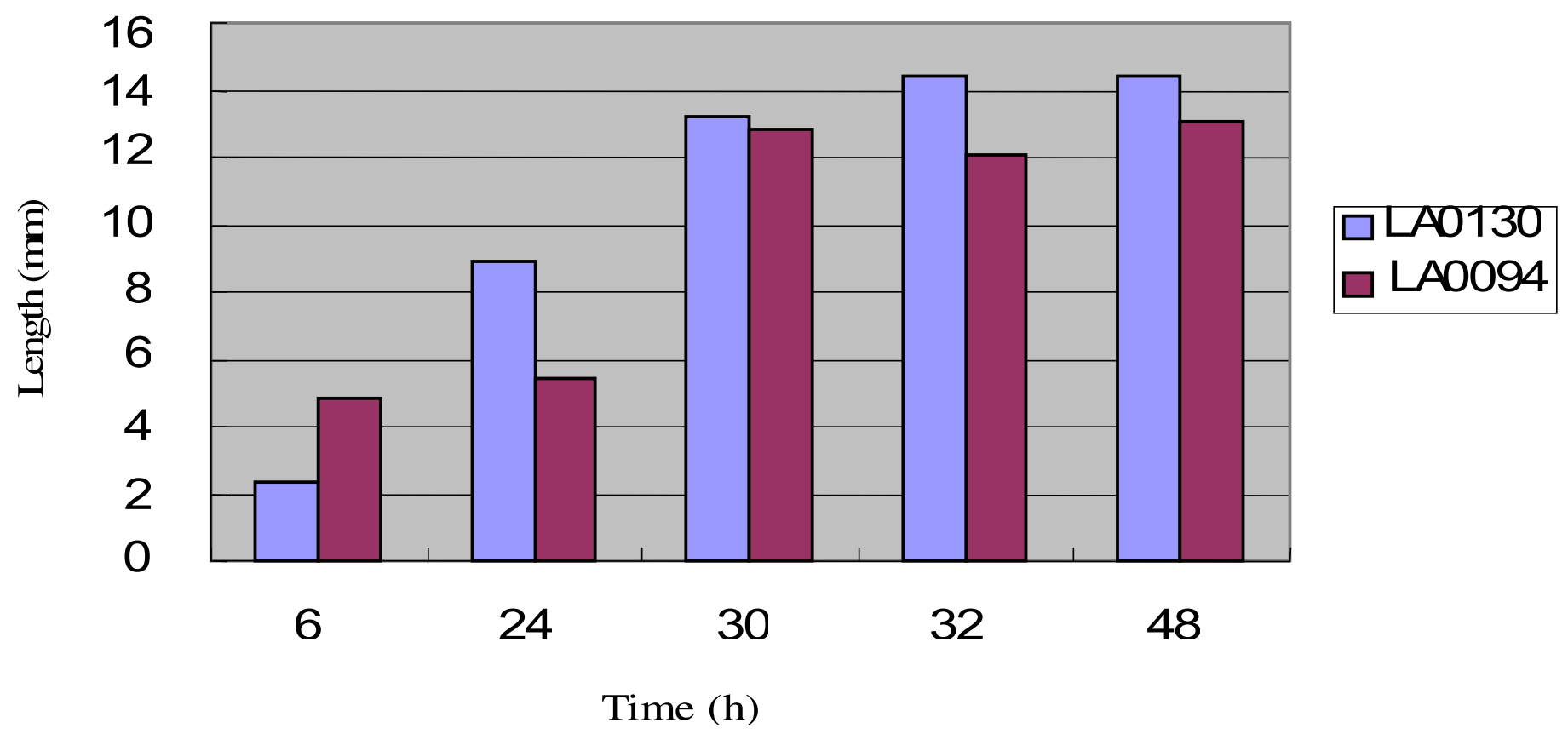

Figure 8. SI and SC pollen tube length in self pollinations.

LAl777 ( S-hab)

LA0130 ( Z S4)

LA0130 ( ZS5)
IHGVWP DKE GTMLQ QCKP KP D YNNF KDKMFN . DLDKNDI IQLKYDE YGRNKO IHGUUP DNKSVVLNNCKNEVLKTSL KD P IKKTELDKR WPQL RYEKIDG IEKO IHGVUP DNKSV ILNNCKMKF L IL YLODKKKS . ELD KRUJPQLRYEKL YGIEKO ihgvwpdnksv lnnek $\mathrm{k} l$ l kdk $\mathrm{k}$ eldkrwpqlryek ygiekq

$\mathrm{C} 2$

LA1777 is-hab i PLWVYQYLKHGSCCOKMYNONTFFL ALL KDRF DLLRTLEMHKIF PGSSY LA0130( ZS4) LAH0130 ( Z55) DL WE KE F LKHGSCS INR YKQE A YF DL A MK IKD RF DL L GTLRNQG I IPGSTY DL WE KE F LKHGSCS INRYKQE AYF DL A MK IKDRF DLL GTLRNQG I IPGSTY dl wekef lkhgses inrykqeayfd lamkikdrfdl lgt lrnggi i pgst y C3 $\mathrm{C4}$

LAl 777 ( S-hab) TFQE IF D WVTÄTOMDPDLKCTK. . GäPELPE IGI LA0130 ( Z\$4) LAO0130 ( 255) ELDD IER I IKTVS IEVP SLKC IQKPL GNVELTE IGI ELDD IER QVVKTVS IEVP SLKC IQKP L GNVELNE I G I elddieravktvsievoslkeiakolanvel eiai 


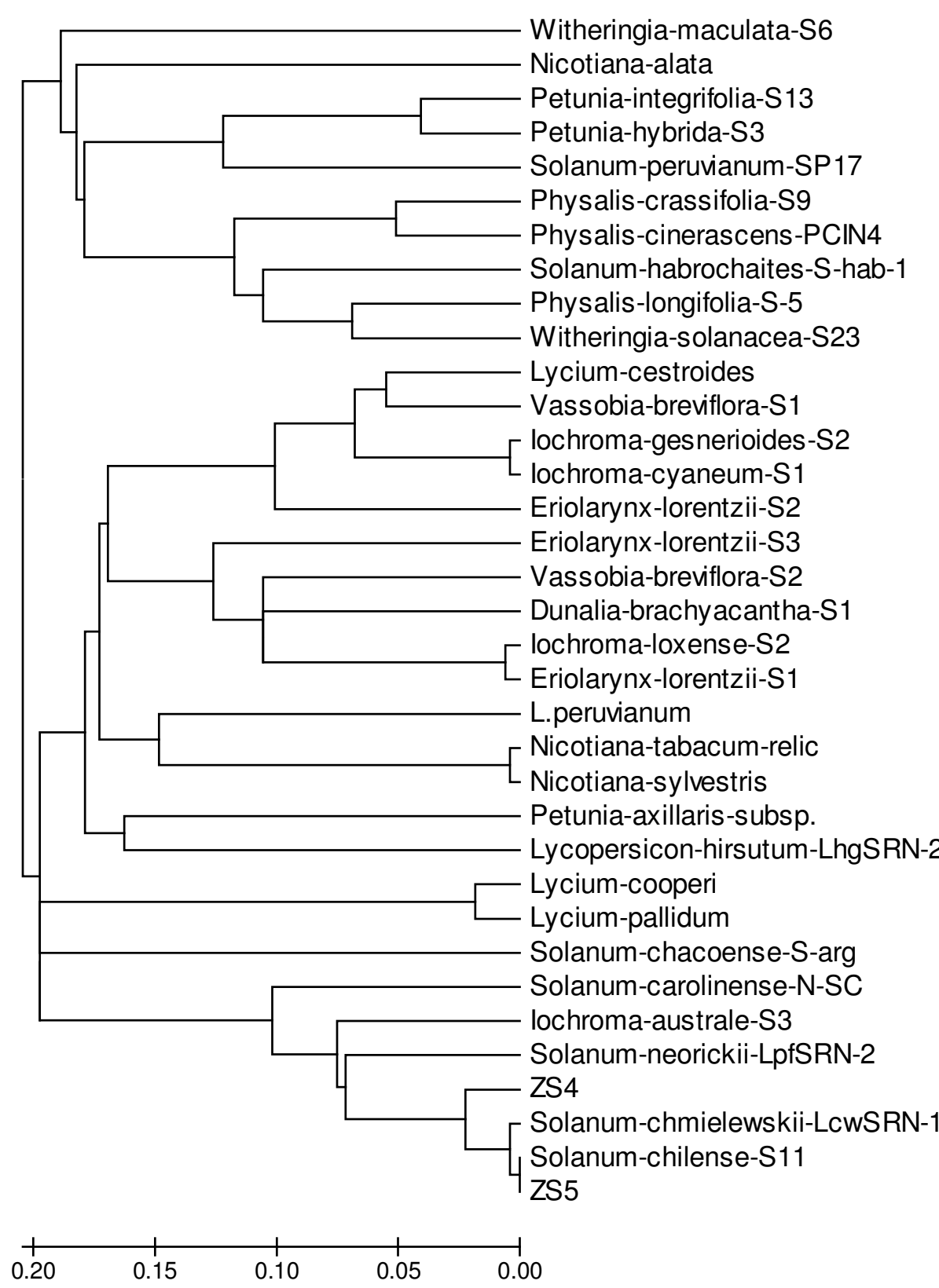

Figure10. Neighbor-joining tree constructed with the S-RNase gene DNA sequences using the PHYLIP program.

Sequences in the tree and their accession numbers are Lycium cestroides (HM195097.1), Lycium cooperi (HM195096.1), Lycium pallidum (HM195095.1), Petunia hybrida S3( U07363.1), Petunia integrifolia S13 (AF301174.1), Solanum peruvianum SP17(HM357228.1), Solanum carolinense N-SC(L40551.1), Solanum chilense S11(EF680110.1), Solanum chacoense S-arg (DQ007316.1), Lycopersicon hirsutum LhgSRN-2(AB072479.1), Solanum chmielewskii LcwSRN-1(AB072477.1), Solanum neorickii LpfSRN-2(AB072476.1), L.peruvianum (X76065.1), Physalis crassifolia S9(L46661.1), Physalis cinerascens PCIN4(AF058933.1), Physalis longifolia S5(AF374420.1), Witheringia solanacea S23(AY454121.1), Witheringia maculate S6(AF102073.1), Nicotiana tabacum relic (AJ011532.1), Nicotiana sylvestris (AJ002296.1), Nicotiana alata (GQ375153.1), lochroma loxense S2(EU382087.1), lochroma gesnerioides S2(EU382083.1), lochroma cyaneum S1(EU382081.1), lochroma australe S3( EU382080.1), Vassobia breviflora S2(EU382085.1), Vassobia breviflora S1(EU382084.1), Dunalia brachyacantha S1(EU382077.1), Eriolarynx lorentzii S3(EU382076.1), Eriolarynxm lorentzii S2(EU382075.1), Eriolarynx lorentzii S1(EU382074.1), Solanum habrochaites Shab-1 (GU361144.1). 


\section{REFERENCES}

Brukhin V, Hernould M, Gonzalez N, Chevalier C, Mouras A (2003).Flower development schedule in tomato Lycopersicon esculentum cv. sweet cherry. Sex Plant Reprod. 15: 311-320.

Boris I, Joshua R K (2001). Evolutionary relationships among selfincompatibility RNases. Proceedings of the national academy of sciences of the united states. $98: 13167-13171$.

Chandra Sekhar KN, Sawhney VK (1984). A scanning electron microscope study of the development and surface feature of floral organs of tomato (Lycopersicon esculentum). Can. J. Bot. 62: 24032413.

Coen E, Meyerowitz EM (1991) .The war of the whorls: genetic interactions controlling flower development. Nature, 353: 31-37.

De Nettancourt D (2001) .Incompatibility in angiosperms. SpingerVerlag, Berlin.

Kondo K, Yamamoto M, Itahashi R, Sato T, Egashira H, Hattori T,Kowyama Y (2002). Insights into the evolution of self-compatibility in Lycopersicon from a study of stylar factors. Plant J. 30(2): 143-153.

Kearns CA, Inouye DW (1993). Techniques for Pollination Biologists. University Press of Colorado, Niwot, CO.

Meyerowitz EM (1998). Genetic and molecular mechanisms of pattern formation in Arabidopsis flower development. J. Plant Res. 111: 233242.

$\mathrm{Ng} \mathrm{M}$, Yanofsky MF (2000). Three ways to learn the ABCs. Curr. Opin. Plant Biol. 3: 47-52.
Rasmussen N, Green PB (1993). Organogenesis in flowers of the homeotic green pistillate mutant of tomato (Lycopersicon esculentum). Am. J. Bot. 80: 805-813.

Sawhney VK, Greyson RI (1972). On the initiation of the inflorescence and floral organs in tomato (Lycopersicon esculentum). Can. J .Bot. 50:1493-1495.

Schneitz K, H_lskamp M, Pruitt RE (1995). Wild-type ovule development in Arabidopsis thaliana: a light microscope study of cleared whole-mount tissue. Plant J. 7: 731-749.

Weigel D, Meyerowitz EM (1994). The ABCs of floral homeotic genes. Cell. 78: 203-209.

Theissen G, Becker A, Di Rosa A, Kanno A, Kim JT, Munster T,Winter $\mathrm{KU}$, Saedler H (2000). A short history of MADS-box genes in plants. Plant Mol. Biol. 42: 115-149. 